\title{
Space allowance and barriers influence cow competition for mixed rations fed on a feed-pad between bouts of grazing
}

\author{
A. D. Hetti Arachchige, ${ }^{*}{ }^{1}$ A. D. Fisher, ${ }^{\star} \dagger$ W. J. Wales, $\ddagger$ M. J. Auldist, $\ddagger$ M. C. Hannah, $\ddagger$ and E. C. Jongman ${ }^{*} \dagger$ \\ ${ }^{*}$ Faculty of Veterinary Science, and \\ †Animal Welfare Science Centre, University of Melbourne, Parkville, Victoria 3010, Australia \\ ‡Department of Environment and Primary Industries, Ellinbank, Victoria 3821, Australia
}

\section{ABSTRACT}

The objective of this experiment was to evaluate how feeding space allowance and provision of feed barriers interact to affect feeding and social behavior of dairy cows fed a partial mixed ration on a feed-pad. The treatments were factorial with 3 feeding space allowances $(0.6,0.75$, or $1.0 \mathrm{~m}$ of trough space per cow) and feed troughs that were either open or had head barriers that physically separated adjacent cows to reduce interactions during feeding. One hundred and forty-four Holstein-Friesian cows in mid lactation were allocated into 12 groups of 12 cows, with 1 of 6 treatments (3 $\times 2$ ) randomly assigned to 2 groups out of 12 . Treatments were changed weekly over 3 wk according to a row-column, crossover design, with week corresponding to rows and group corresponding to columns. Thus, the design included 2 replicated groups per treatment in each week. Grazed pasture intake was approximately $6.1 \mathrm{~kg}$ of dry matter (DM)/cow per day, supplemented with $3.5 \mathrm{~kg}$ of DM/cow per day of wheat (Triticum aestivum) grain fed during milking and $10.7 \mathrm{~kg}$ of DM/ cow per day of a mixed ration offered on the feed-pad after each milking. The experiment comprised a 7 -d pre-experimental period followed by a 21-d experimental period. The social hierarchy within each group was determined before the experiment commenced. Feeding and social behaviors of cows were analyzed using video recordings and the changes in heart rate and heart rate variability were determined using heart rate monitors. Data were analyzed using mixed effect models by REML. When feeding space allowance was increased, we observed an increase in the time a cow spent feeding and a decrease in the number of feeding bouts in relation to the total time feed was available, particularly in subordinate cows. The number of aggressive behaviors and displacements decreased when space allowance increased. In addition, HR was reduced and the reduction was more pronounced in subordinate cows compared

Received October 2, 2013.

Accepted March 5, 2014.

${ }^{1}$ Corresponding author: anoma.arachchige@unimelb.edu.au with dominant cows. Use of feed barriers increased cow feeding time and decreased the number of feeding bouts in relation to the total time feed was available, particularly in subordinate cows, and reduced the number of cow displacements during feeding. We conclude that increasing the feeding space from 0.6 to 0.75 to $1.0 \mathrm{~m}$ reduces aggressive interactions and improves cow feeding behavior, with the effects being greatest for subordinate cows. The use of feed barriers further reduces competition at the feed trough in a partial mixed ration feeding system.

Key words: partial mixed ration, feeding space, feed barrier, competition

\section{INTRODUCTION}

Grazed pasture is a significant source of nutrients for dairy cattle in many parts of the world, including Australia, because of its inherent low cost (Doyle and Stockdale, 2011). However, the variable rainfall in pasture-based dairying regions can increase the variability in pasture supply and lead to increased reliance on purchased supplements to meet the nutritional requirements of the milking herd, especially in systems with a high stocking rate. Traditional systems for feeding supplements to grazing cows involve feeding cereal grain or pelleted concentrates in the milking parlor and conserved forages in the paddock. More recently, systems that offer cows high amounts of supplements as a mixed ration on a feed-pad between bouts of grazing have become increasingly common; such systems are defined as partial mixed ration (PMR) systems (Bargo et al., 2002a). These systems can offer milk production advantages over "slug" feeding of concentrates during milking (Bargo et al., 2002b; Auldist et al., 2013), with no indication of negative consequences for cow welfare (Hetti Arachchige et al., 2013).

One of the primary objectives of dairying is to profitably turn feed into milk. One way to contribute to improved profitability is to ensure that socially lowranked cows are able to satisfy their DMI demands. However, feed intake can vary markedly between cows when they are fed as a group (Friend et al., 1977). 
One of the potential causes for this variation in DMI is competition between cows during feeding (Olofsson, 1999). In turn, the amount of available feeding space per cow is one of the major factors influencing the level of competition during feeding (DeVries et al., 2004), and inadequate feeding space can be a cause of stress associated with aggression in group-fed dairy cows (Morgan and Tromborg, 2007).

Increased aggression and displacements at the feed trough when cows are overcrowded have been noted by several researchers (DeVries and von Keyserlingk, 2006; Huzzey et al., 2006; Proudfoot et al., 2009). von Keyserlingk and Weary (2010) reviewed recent empirical work addressing how changes in management affect feeding behavior of group-fed dairy cows and reported that when a competitive situation exists at the feed bunk, dominant cows spend more time eating than socially low-ranked cows, which may consequently have lower DMI and produce less milk, affecting overall herd production. Olofsson (1999) further reported that dominant cows were recorded as being those cows that gained eating time at the higher competition level while subordinate cows were forced to alter the allocation of their feed consumption to less preferred hours of the day. This is of concern in dairy operations when access to feed is limited (Dickson et al., 1967; Greter et al., 2013), as is the case with cows consuming nutrientdense mixed rations on a feed-pad for only part of the day, without the opportunity to shift their feeding times. Furthermore, at reduced pasture allowances, subordinate cows are less able to compensate for the reduced supplement intake by consuming more pasture.

One strategy for reducing competition between cows on a feed-pad is to provide adequate feeding space per cow. Although current industry recommendations for feed-pads in Australia advise a feeding space of 0.60 to $0.76 \mathrm{~m}$ per cow (O'Keefe et al., 2010), there is no evidence to substantiate the relationship between feeding space and competition on the feed-pad in a PMR feeding system. In reality, feeding space allowances vary considerably from farm to farm due to changes in herd size, farm facilities, and different management decisions (Davison and Andrews, 1997). In this experiment, we evaluated the effects of different feeding space allowances on a feed-pad on feeding and social behaviors in lactating dairy cows in a PMR feeding system.

Another way of reducing competition during feeding is to provide a physical barrier that provides a separation between adjacent cows (Endres et al., 2005; Huzzey et al., 2006). Such barriers may reduce the negative effects of crowding at a given feeding space, providing cows more equal access to feed on the feedpad. Because inadequate feeding space is a potential stressor during group-feeding of dairy cows, heart rate
(HR) and heart rate variability (HRV) may be suitable and noninvasive biological responses to measure the functional regulatory characteristics of autonomic nervous system in response to a stressor (Moberg and Mench, 2000; von Borell et al., 2007). Heart rate and HRV have been used as indicators of acute and chronic stress in dairy cows to assess their welfare under different housing and management conditions (Hagen et al., 2005; Arnold et al., 2007; Gygax et al., 2008).

The current experiment was conducted to test the following hypotheses: (1) that increasing the feeding space allowance from 0.6 to 0.75 to $1.0 \mathrm{~m}$ per cow on a feed-pad would increase cow feeding time and decrease feed bout frequency as a result of decreased agonistic social interactions in group-fed dairy cows; (2) that at a given feeding space allowance, feed barriers that provide physical separation between adjacent cows would increase cow feeding time and decrease feeding bout frequency as a result of fewer agonistic interactions; and (3) that increasing the feeding space allowance from 0.6 to 0.75 to $1.0 \mathrm{~m}$ along with provision of feed barriers on a feed-pad would decrease the level of competition among cows, resulting in lower physiological stress responses as measured by HR and HRV.

\section{MATERIALS AND METHODS}

This experiment was conducted at the Department of Environment and Primary Industries (DEPI), Ellinbank Centre, Victoria, Australia $\left(38^{\circ} 24^{\prime} \mathrm{S}, 145^{\circ} 94^{\prime} \mathrm{E}\right)$ during April and May (autumn) 2012, with approval from the DEPI Agricultural Research and Extension Animal Ethics Committee and in accordance with the Australian Code of Practice for the Care and Use of Animals for Scientific Purposes (National Health and Medical Research Council, 2004).

\section{Cows and Design}

One hundred and forty-four multiparous HolsteinFriesian dairy cows in mid lactation were used. Cows grazed pasture for approximately $19 \mathrm{~h} / \mathrm{d}$. This was supplemented with wheat (Triticum aestivum) grain fed individually to cows during milking and a mixed ration offered on a feed-pad after each milking. All cows were milked twice daily between 0700 and $0830 \mathrm{~h}$ and 1500 and $1630 \mathrm{~h}$. Immediately before the experiment, cows were allotted into 12 groups of 12 cows, with groups balanced for (mean \pm SD) age $(5.8 \pm 1.87 \mathrm{yr})$, BCS on an 8-point scale (4.4 \pm 0.22 ; Earle, 1976), body width at the widest point $(75 \pm 3.3 \mathrm{~cm})$, BW $(586 \pm 46.5$ $\mathrm{kg})$, DIM $(180 \pm 19)$, and milk yield in the previous lactation $(7,518 \pm 1,363 \mathrm{~kg} / \mathrm{cow})$, using a method by Harville (1974) implemented in GenStat software (15th 
ed., 2012; VSN International, Hemel Hempstead, UK). The grazed cows were separated into groups of 12 cows before feeding on the feed-pad.

The treatment structure was factorial with 3 feeding space allowances $(0.6,0.75$, and $1.0 \mathrm{~m}$ per cow $)$ by either an open feed trough or a feed trough with head barriers to separate adjacent cows during feeding. The 0.6-m treatment approximated the minimum standard typically recommended for feed-pads in Australia (O'Keefe et al., 2010) and the $0.75-\mathrm{m}$ treatment was the mean cow body width, representing the minimum feeding space per cow required to feed all cows simultaneously. The $1.0-\mathrm{m}$ treatment was chosen to provide a contrast within a range that is still relevant to producers. One of 6 treatments $(3 \times 2)$ was randomly assigned to each of 2 groups. The experiment was conducted over 28 $\mathrm{d}$, which comprised a 7-d pre-experimental period followed by a 21-d data collection period. Treatments were changed weekly over a period of $3 \mathrm{wk}$ according to a row-column, crossover design, with week corresponding to rows and group corresponding to columns (Table 1 ). Treatments were randomized subject to this design by permutation of columns and permutation of rows. Hence, each group of 12 cows was exposed to 3 treatments during this 3 -wk period (in an incomplete block design). Throughout this experiment, the locations of the 12 groups on the feed-pad did not change but the location of treatments changed due to the weekly crossover, minimizing confounding effects between treatments and location on the feed-pad.

\section{Pasture and Supplements}

Mean intake of grazed perennial ryegrass (Lolium perenne L.) was approximately $6.1 \mathrm{~kg}$ of $\mathrm{DM} / \mathrm{cow}$ per day and contributed about $30 \%$ of cow's daily DMI. Pre- and postgrazing pasture mass was estimated daily using a C-Dax pasture meter (Pasturemeter XP1, C-Dax Ltd., Palmerston North, New Zealand) to calculate mean daily pasture DMI for 144 cows. The pasture meter was calibrated for each new set of paddocks the cows entered. Rolled wheat grain, which contributed $25 \%$ of total supplement DMI (3.5 kg of DM/cow per day), was fed individually to cows twice daily in the milking parlor with a vitamin and mineral pellet (Nutrified Hi-Milker, Debenham Australia Pty Ltd., Leongatha, Victoria, Australia). The remaining supplements (10.7 $\mathrm{kg}$ of $\mathrm{DM} /$ cow per day) were fed as a mixed ration on a feed-pad immediately after each milking (half the daily ration was fed following each milking). The mixed ration comprised corn (Zea mays) silage (30\% of total DM supplement), alfalfa (Medicago sativa) hay (20\% of total DM supplement), solvent-extracted canola (Brassica rapa) meal ( $13 \%$ of total DM supplement), and corn grain (12\% of total DM supplement) that were mixed and chopped in a feed wagon, (model K160; Richard Keenan and Co. Ltd., Co. Carlow, Ireland) before being presented on the feed-pad. Water was added to the ration such that the final DM concentration of the ration was approximately $500 \mathrm{~g} / \mathrm{kg}$. Refusals of mixed ration, if any, were recorded daily to estimate the daily supplement intake by each group of 12 cows. Cows were given access to pasture after they had consumed their mixed ration on the feed-pad. Cows had access to water troughs located in and adjacent to the dairy and in laneways adjacent to the paddocks.

\section{Feed-Pad and Feed Barriers}

The feed-pad was a permanent feed-out area with a concrete surface and had a total length of $50 \mathrm{~m}$ and width of $20 \mathrm{~m}$. There were 2 parallel concrete feed troughs of $50 \mathrm{~m}$ long and $1 \mathrm{~m}$ wide on the feed-pad separated by $9 \mathrm{~m}$ (width of cow standing alley was 4.5 $\mathrm{m})$. Six groups were allotted to each trough, which was divided in 6 using one longitudinal partition and 2 lateral partitions (wooden), facilitating 3 groups per side and ensuring that cows could not consume food from the adjacent or opposite groups. Movable hoop-shaped metal palisades were screwed to the concrete trough as feed barriers. Cows inserted their heads through a space of $0.2 \mathrm{~m}$ between 2 palisades to reach the feed in the trough. The spacing and location of the palisades were changed weekly according to the spacing and barrier

Table 1. Diagrammatic representation of the experimental design, showing grouping of 144 cows into twice-replicated 6 treatments ${ }^{1}$ that were crossed over weekly in an incomplete block design (each group was exposed to only 3 treatments during the data collection period of 3 wk)

\begin{tabular}{|c|c|c|c|c|c|c|c|c|c|c|c|c|}
\hline $\begin{array}{l}\text { Treatment } \\
\text { allocation }\end{array}$ & \multicolumn{6}{|c|}{ Replicate $1(\mathrm{n}=18)$} & \multicolumn{6}{|c|}{ Replicate $2(\mathrm{n}=18)$} \\
\hline Number of cows & 12 & 12 & 12 & 12 & 12 & 12 & 12 & 12 & 12 & 12 & 12 & 12 \\
\hline Week 2 & B & $\mathrm{E}$ & $\mathrm{F}$ & A & $\mathrm{C}$ & D & B & $\mathrm{C}$ & D & $\mathrm{F}$ & A & $\mathrm{E}$ \\
\hline Week 3 & $\mathrm{C}$ & B & A & D & $\mathrm{E}$ & $\mathrm{F}$ & D & $\mathrm{F}$ & A & $\mathrm{E}$ & B & $\mathrm{C}$ \\
\hline
\end{tabular}

${ }^{1}$ Treatments: $\mathrm{A}=0.6-\mathrm{m}$ feeding space with no barriers; $\mathrm{B}=0.6$ - $\mathrm{m}$ feeding space with barriers; $\mathrm{C}=0.75$ - $\mathrm{m}$ feeding space with no barriers; $\mathrm{D}=$ 0.75- $\mathrm{m}$ feeding space with barriers; $\mathrm{E}=1.0-\mathrm{m}$ feeding space with no barriers; $\mathrm{F}=1.0$ - $\mathrm{m}$ feeding space with barriers. 
Table 2. Mean ( \pm SD) DIM, age, BW, BCS, ${ }^{1}$ body width at the widest point, cumulative lactation yields of milk, and the percentage of protein and fat contents in milk for dominant (3 cows per group) and submissive (3 cows per group) cows in the 12 groups immediately before the commencement of the experiment

\begin{tabular}{|c|c|c|c|c|c|c|c|c|}
\hline $\begin{array}{l}\text { Social rank } \\
\text { of cows }\end{array}$ & $\begin{array}{l}\mathrm{BW} \\
(\mathrm{kg})\end{array}$ & $\mathrm{BCS}$ & $\begin{array}{l}\text { Body width } \\
(\mathrm{cm})\end{array}$ & $\begin{array}{l}\text { Age } \\
\text { (yr) }\end{array}$ & DIM & $\begin{array}{l}\text { Milk } \\
(\mathrm{kg})\end{array}$ & $\begin{array}{l}\text { Protein } \\
(\%)\end{array}$ & $\begin{array}{l}\text { Fat } \\
(\%)\end{array}$ \\
\hline Dominant & $611 \pm 53.1$ & $4.5 \pm 0.24$ & $74 \pm 3.6$ & $5.4 \pm 1.79$ & $181 \pm 18.3$ & $7,599 \pm 776$ & $3.4 \pm 0.23$ & $5.1 \pm 0.62$ \\
\hline Submissive & $581 \pm 38.3$ & $4.4 \pm 0.25$ & $74 \pm 3.3$ & $6.1 \pm 1.87$ & $178 \pm 19.7$ & $7,337 \pm 1,234$ & $3.3 \pm 0.20$ & $4.7 \pm 0.73$ \\
\hline
\end{tabular}

${ }^{1}$ Measured on an 8-point scale (Earle, 1976).

${ }^{2}$ Social hierarchy in each group of 12 cows was determined using index of success (IS; Mendl et al., 1992; DeVries et al., 2004) during the preexperimental period; the 3 most dominant and the 3 most subordinate cows were identified for each group.

treatment allocations. Feed was placed only within the space created by the partitions. Groups were separated by electric tapes and removable metal gates.

\section{Pre-experimental Period}

During the pre-experimental week, cows were fed a mixed ration on the feed-pad in their assigned groups of 12 cows at a feeding space of $0.75 \mathrm{~m}$ per cow with no feed barriers, to get them accustomed to the feed-pad feeding routine and to establish a hierarchy within their allotted groups. During this adaptation period, the social hierarchy within each group was determined using the index of success (IS; Mendl et al., 1992; DeVries et al., 2004) calculated for each cow fed a mixed ration at an experimentally reduced space allowance of 0.2 $\mathrm{m}$ per cow over 3 feeding sessions. Previous research investigated reducing feeding space from 0.81 to 0.21 $\mathrm{m}$ per cow (Huzzey et al., 2006) and 0.56 to $0.2 \mathrm{~m}$ per cow (O'Connell et al., 2010) and found that reducing feeding space to $0.2 \mathrm{~m}$ leads to increased competition among group-fed dairy cows. During the hierarchy testing, agonistic interactions between cows in each group were recorded by video for the first $30 \mathrm{~min}$ of each feeding session and then the feeding space was widened from 0.2 to $0.75 \mathrm{~m}$ for the rest of the feeding session to avoid any negative effects on supplement intake. Moreover, during the hierarchy testing, all cows were offered $6 \mathrm{~kg}$ of $\mathrm{DM} /$ cow per day of pasture silage in the allotted paddocks to further avoid any negative effects on their daily DMI.

Following the hierarchy testing, recorded videos were analyzed for number of displacements exhibited by cows to calculate the IS for each cow and then to determine their hierarchical position within the group of 12 cows. A displacement was noted when a butt or a push from the instigator resulted in the complete withdrawal of the reactor's head from the feed trough (DeVries et al., 2004). Hence, IS was calculated as follows:

$$
\begin{aligned}
\text { IS }= & \frac{\text { No. of cows that an individual is able to displace }}{\text { No. of cows that an individual is able to displace and }} \times 100 \% \\
& \text { No. of cows that are able to displace the individual }
\end{aligned}
$$

Depending on the calculated IS, the 3 most subordinate cows and the 3 most dominant cows were randomly paired into 3 pairs (each pair including 1 dominant and 1 subordinate) within each group and were fitted with heart rate monitors (Polar RS800CX model; Polar Electro Oy, Kempele, Finland) to monitor HR responses during the data collection phase. Mean $( \pm \mathrm{SD})$ values for DIM, age, BW, BCS (on an 8-point scale), body width at the widest point, cumulative lactation yields of milk, and the percentages of protein and fat contents in milk for dominant and submissive cows are presented in Table 2.

\section{Experimental Period}

Following the pre-experimental period, 12 groups were assigned to their treatments and data were collected over $3 \mathrm{wk}$. During each week, cows were given $4 \mathrm{~d}$ of adjustment followed by $3 \mathrm{~d}$ of data collection. Thus, cows were adapted to the assigned treatments during the first $4 \mathrm{~d}$ of each week, minimizing the possibility of treatment carryover from the previous week.

Behavioral Recording. Feeding and social behavior of cows was recorded by video during the morning and afternoon feeding sessions. Six cameras (model 104-279 Sony 550TVL; Korea Communication Electronics, Incheon, Korea), fitted with a 2.97-mm lens, were installed $5 \mathrm{~m}$ above the feed troughs, so that the entire feeding area (feed and cow alleys) was visible. An identification number was painted on the back of each cow to assist in identifying cows during analysis of the videos.

Automated Recording of $H R$ and Interbeat Interval. Changes in HR and interbeat interval (IBI) in dominant and subordinate cows in different treatments were monitored using $24 \mathrm{HR}$ monitors that have been validated for use in dairy cows (Mohr et al., 2002; Gygax et al., 2008; Stewart et al., 2008). After each milking, the predetermined dominant and subordinate cows were separated and the HR monitors were applied to each cow in a cattle crush. Electrodes were positioned on the left side of the chest with one electrode placed close to the sternum and the other over 
the right scapula (von Borell et al., 2007). The cow's skin was shaved where the electrodes were placed to enhance conductivity between the electrodes and the skin. An ample amount of neuro-diagnostic electrode paste (Ten20; Weaver and Company, Aurora, CO) was applied to the electrodes before application to further improve electrode-skin contact. The electrodes were held in position with an elastic girth strap to which the transmitter belt was attached. The receiver was fitted to the girth strap to ensure continuous signal receipt. Cows were familiarized with the cattle crush and the procedure for applying HR monitors over 3 sessions before data collection. During each week of data collection, 1 randomly selected pair from each group was monitored on d 5 for both morning and afternoon feeding sessions. The monitors were swapped to the second and third pairs of cows, respectively, from the same subgroup on d 6 and 7 during that week. After this was completed, the treatments were switched between the subgroups and the same procedure was then repeated over the remaining 2 wk of the experimental period.

\section{Data Management}

Cow Behavioral Data. For each cow during each feeding session, behavioral elements were recorded continuously from the video recordings by a single observer. Analysis of each video recording commenced $\left(\mathrm{t}_{\text {start }}\right)$ when all cows in the group of 12 arrived at the feeding alley and finished $\left(t_{\text {finish }}\right)$ when more than half of the group withdrew from the feed trough, indicating that most of the available food was consumed.

A cow was classified as feeding when its head was placed in the feed trough or chewing was observed. When the time interval between the start of a feeding activity and complete withdrawal from the feed trough was longer than $30 \mathrm{~s}$, it was considered as a feeding bout. Total time spent feeding ( $\min )$, mean bout duration (min), and total number of feeding bouts were calculated for each cow at each feeding session. The total time feed was available for each group at each feeding session was also recorded $\left(t_{\text {finish }}-t_{\text {start }}\right)$, and the feeding time of each cow was expressed as a percentage time spent feeding relative to the total time feed was available in the feed trough (feeding time \%).

Agonistic behaviors, defined as any social behavior associated with conflict or fighting between 2 individual cows (Dickson et al., 1967), were counted for each individual cow at each feeding session. Behaviors such as butting, pushing, fighting, and threat and avoidance were recorded as agonistic behaviors. Butting was recorded when a dominant cow's head came in contact with a subordinate cow that was feeding, resulting in the subordinate cow completely withdrawing its head from the feed trough. Pushing behavior was characterized by a dominant cow physically displacing a subordinate cow with some part of the body other than the head. Fighting referred to head-to-head combat between 2 cows with no clear-cut winner. Agonistic behaviors without physical contact were considered to be threat and avoidance. After each feeding session, for each individual cow, all the dominant acts were summed and grouped as aggressive behaviors and all the forced displacements were summed and grouped as submissive behaviors.

From these behavioral data, the following variables were calculated for each cow for each feeding session: (1) percentage time spent feeding relative to the total time feed was available in the feed trough (feeding time $\%$ ); (2) feeding bout frequency; (3) mean bout duration (min); (4) total number of aggressive behaviors; and (5) total number of submissive behaviors.

$\boldsymbol{H R}$ and $\boldsymbol{H R} \boldsymbol{V}$. The receiver recorded heart beat and displayed HR in beats per minute and IBI in milliseconds. The recorded data were transferred to a computer after each feeding session. An automatic correction for artifacts and ectopic beats was carried out using the algorithm and software provided by the manufacturer. In addition, manual inspection of these graphical data was done to edit remaining artifacts by replacing aberrant data with linearly interpolated values. Finally, only such tachograms with corrected anomalies of less than $5 \%$ were included in further analysis (Mohr et al., 2002; von Borell et al., 2007; Gygax et al., 2008).

In addition to absolute $\mathrm{HR}$, the square root of the mean of the sum of squares of differences between successive IBI (RMSSD) was analyzed as an HRV parameter. The RMSSD is the most informative and primary time domain measure used to estimate the short-term, high frequency, beat-to-beat variations that strongly reflect vagal regulatory activity (Malik et al., 1996; von Borell et al., 2007; Gygax et al., 2008); it is thus highly correlated to other HRV measures such as frequency domain parameters (high-frequency-norm, low-frequency/high-frequency) and nonlinear domain parameters (recurrence, determinism, entropy, and maxline; Hagen et al., 2005).

The RMSSD was calculated using Kubios HRV software (version 2.1; Biosignal Analysis and Medical Imaging Group, Department of Physics, University of Eastern Finland, Kuopio, Finland; Sloten et al., 2009) that was based on the guidelines given by Malik et al. (1996). Thus, the RMSSD was calculated as

$$
\operatorname{RMSSD}=\sqrt{\frac{1}{N-1} \sum_{j=1}^{N-1}\left(R R_{j+1}-R R_{j}\right)^{2}},
$$


where $R R_{j}$ denotes the value of $j$ th $\mathrm{RR}$ interval (i.e., $\mathrm{R}$ wave to $\mathrm{R}$ wave interval or IBI), and $N$ is the total number of successive intervals.

Cow behavior appeared to be undisturbed by the application of HR monitors as cows had been previously accustomed to wear these data loggers. The mean HR and RMSSD calculated for the last 5 min in the holding yard, before walking to the feed-pad, was used as baseline data. During this period, the cow was inactively standing in the holding yard after the application of the monitor.

Thus, from HR monitor data, the variables calculated for each cow for each feeding session and the covariate period were mean HR and RMSSD.

\section{Statistical Analysis}

For the analysis of feeding behavior, social behavior, and cardiac responses, the group of 12 cows was considered as the experimental unit and the analyses were conducted separately using mixed effects models by REML (GenStat, 2012).

For interval scale data such as feeding time percentage and feeding bout duration, the model was defined with factorial fixed effects for space allowance, presence or absence of barriers, time of day (a.m. or p.m.), and social rank of the cow (dominant, subordinate, or neither). A blocking factor of week was also included as a fixed effect. Random effects consisted of the nested effects of time of day within day within week, all crossed with the nested effects of cow within group, in accordance with the experimental design.

For count data such as number of aggressive and submissive behaviors and number of feeding bouts, data were first averaged within groups over day and over cows within social rank, before statistical analysis, to result in approximately normally distributed and interval-scale variables. The mixed effects models were defined with factorial fixed effects for space allowance, presence or absence of barriers, and social rank of the cow. A blocking factor of week was also included as a fixed effect. Random effects consisted of the nested effects of time of day within week, all crossed with group. To test for treatment effects on between-cow variability, the same mixed model was applied to standard deviations in place of the averaged data.

For HR and RMSSD data, the mixed effects model included a linear covariate for mean baseline data (HR or RMSSD) of each animal, measured before the animal entering the feed-pad, and factorial fixed effects for space allowance, by presence or absence of barriers, by time of day, and by social rank of the cow. A blocking factor for week was also included as a fixed effect. The mixed model included random effects for group, group by week, cow, and crossed terms for cow and time of day, within group by day. Negative estimated components of variance were allowed except where they produced numerical singularity causing the algorithm to fail. For this reason, a term for time of day within day was excluded from the random effects.

Residuals were examined graphically for normality of distribution using histograms and with the normal quantile plots. The homoscedasticity of the population was checked with the fitted values versus residuals graphs. Data transformations were applied if necessary to conform to distributional assumptions.

\section{RESULTS}

\section{Feeding Behavior}

The effects of feeding space allowance and provision of feed barriers along with the social rank of cows on cow feeding behavior are presented in Table 3. These results are presented and discussed as mean values per cow per feeding session (2 feeding sessions per day), unless otherwise stated.

With the increase of feeding space from 0.6 to 0.75 to $1.0 \mathrm{~m}$, we observed an increase in the percentage of time a cow spent feeding relative to the total time feed was available in the feed trough $(92,95$, and $96 \%$ respectively; $P<0.001)$ and its standard deviation within the group of 12 decreased $(P<0.001)$. The mean total time that feed was available (mean $\pm \mathrm{SD}$ ) at feeding space allowances of $0.6,0.75$, and $1.0 \mathrm{~m}$ were $25 \pm 2,24$ \pm 2 , and $25 \pm 3$ min per session respectively. The mean feeding bout frequency $(P<0.001)$ and its standard deviation $(P=0.005)$ were lowest at the highest feeding space $(1.0 \mathrm{~m})$ compared with the other 2 treatments $(0.6$ and $0.75 \mathrm{~m})$. At a given feeding space allowance, feed barriers increased feeding time percentage by 1 percentage unit $(P=0.042)$ and decreased feeding bout frequency by $7.5 \%(P=0.033)$. Irrespective of the other main effects, dominant cows had a higher feeding time percentage, a lower feeding bout frequency, and a longer mean feeding bout duration over subordinate cows $(P<0.001)$.

We detected an interaction $(P=0.002)$ between feeding space allowance and the social rank of cows on feeding time percentage (Table 4). Although the increase in feeding time percentage in dominant cows was not significant, subordinate cows showed a significant increase with the increase of feeding space allowance. Further, the interaction between feed barrier provision and social rank of cows affected feeding time percentage $(P<0.001)$. Although it did not differ among dominant cows, subordinate cows exhibited a 3 -unit 
Table 3. The effects of feeding space allowance and use of feed barriers on feeding behaviors of group-fed dairy cows $(\mathrm{n}=18)$ on a feed-pad ${ }^{1}$

\begin{tabular}{|c|c|c|c|c|c|c|c|c|c|c|}
\hline \multirow{2}{*}{$\begin{array}{l}\text { Feeding behavior parameters } \\
\text { per feeding session }\end{array}$} & \multicolumn{10}{|c|}{ Main effect } \\
\hline & $0.6 \mathrm{~m}$ & $0.75 \mathrm{~m}$ & $1.0 \mathrm{~m}$ & $P$-value & Yes & No & $P$-value & Dominant & Subordinate & $P$-value \\
\hline \multicolumn{11}{|l|}{$\overline{\text { Feeding time percentage }^{2}}$} \\
\hline Mean & $92^{\mathrm{a}}$ & $95^{\mathrm{b}}$ & $96^{\mathrm{c}}$ & $<0.001$ & $95^{\mathrm{b}}$ & $94^{\mathrm{a}}$ & 0.042 & $96^{\mathrm{b}}$ & $91^{\mathrm{a}}$ & $<0.001$ \\
\hline $\mathrm{SD}^{3}$ & $7.3^{\mathrm{c}}$ & $5.9^{\mathrm{b}}$ & $3.9^{\mathrm{a}}$ & $<0.001$ & 4.9 & 5.8 & 0.065 & $4.1^{\mathrm{a}}$ & $7.6^{\mathrm{b}}$ & $<0.001$ \\
\hline SD & $1.2^{\mathrm{b}}$ & $1.1^{\mathrm{b}}$ & $0.8^{\mathrm{a}}$ & 0.005 & 1.0 & 1.1 & 0.114 & $0.6^{\mathrm{a}}$ & $1.4^{\mathrm{b}}$ & $<0.001$ \\
\hline \multicolumn{11}{|l|}{ Feeding bout length (min) } \\
\hline Mean & $5.8^{\mathrm{a}}$ & $6.0^{\mathrm{a}}$ & $6.8^{\mathrm{b}}$ & 0.038 & 6.5 & 6.0 & 0.146 & $7.0^{\mathrm{b}}$ & $5.1^{\mathrm{a}}$ & $<0.001$ \\
\hline SD & 1.7 & 1.5 & 1.5 & 0.192 & 1.6 & 1.5 & 0.136 & $1.4^{\mathrm{a}}$ & $1.7^{\mathrm{b}}$ & $<0.001$ \\
\hline
\end{tabular}

${ }^{a-c}$ Within rows, means with different superscripts are significantly different $(P<0.05)$.

${ }^{1}$ Data are predicted means and SD.

${ }^{2}$ Percentage of individual feeding time to total group feeding time.

${ }^{3}$ Indicates cow-to-cow variation of a relevant variable within the group of 12 cows at each treatment.

${ }^{4}$ Number of feeding bouts per feeding session.

increase in feeding time percentage with the presence of feed barriers.

\section{Social Behavior}

The effects of feeding space allowance and provision of feed barriers on aggressive and submissive behaviors exhibited by these group-fed dairy cows are presented in Table 5. These results are presented and discussed as mean values per cow per feeding session.

With the increase of feeding space from 0.6 to 0.7 to 1 $\mathrm{m}$ per cow, the mean number of aggressive behaviors $(P$ $<0.030)$ and the mean number of submissive behaviors $(P<0.001)$ decreased. Although the mean number of aggressive behaviors was not affected, the mean number of submissive behaviors decreased $(P=0.029)$ with the provision of feed barriers, irrespective of the amount of feeding space provided. Dominant cows exhibited more aggressive behavior $(P<0.001)$, whereas subordinate cows showed more submissive behaviors $(P<0.001)$ during a feeding session, irrespective of other main effects. These findings reasserted the hierarchical orders established during the pre-experimental period.

\section{$H R$ and HRV}

The effects of feeding space allowance and use of feed barriers on physiological stress as measured by HR and HRV (calculated as RMSSD) are reported in Table 6 . Mean HR was lowest $(90$ beats $/ \mathrm{min} ; P<0.001)$ for cows in the treatment with the highest space allowance $(1.0 \mathrm{~m})$ and did not differ between other 2 treatments $(0.6 \mathrm{~m}=93$ beats $/ \mathrm{min}, 0.75 \mathrm{~m}=94$ beats $/ \mathrm{min})$. The RMSSD was not affected by the feed space allowance $(P=0.15)$. Neither mean HR $(P=0.354)$ nor RMSSD $(P=0.057)$ was affected by the presence of feed barriers at a given feeding space allowance on the feed-pad. Compared with dominant cows, subordinate cows had higher HR $(P<0.001)$ and lower values for RMSSD $(P$ $=0.014)$ across all treatments.

Table 4. Interaction effects of (1) feeding space allowance $\times$ social rank of cows and (2) provision of feed barriers $\times$ social rank of cows on feeding time percentage on the feed-pad ${ }^{1}$

Interaction effects on feeding time ${ }^{2}(\%)$

\begin{tabular}{|c|c|c|c|c|c|c|c|c|c|}
\hline \multirow{3}{*}{$\begin{array}{l}\text { Social rank of cows } \\
\text { (within-group) }\end{array}$} & \multicolumn{9}{|c|}{ Interaction effects on feeding time ${ }^{2}(\%)$} \\
\hline & \multicolumn{5}{|c|}{ Feeding space per cow } & \multicolumn{4}{|c|}{ Provision of feed barriers } \\
\hline & $0.6 \mathrm{~m}$ & $0.75 \mathrm{~m}$ & $1.0 \mathrm{~m}$ & $P$-value & $\mathrm{SED}^{3}$ & Yes & No & $P$-value & $\mathrm{SED}^{3}$ \\
\hline Dominant & 95 & 96 & 97 & $<0.002$ & $0.85^{*}-1.01 \dagger$ & 96 & 96 & $<0.001$ & $0.70 \ddagger-0.83 \#$ \\
\hline Subordinate & 87 & 91 & 94 & & & 92 & 89 & & \\
\hline
\end{tabular}


Table 5. The effects of feeding space allowance and provision of feed barriers on social behaviors of group-fed dairy cows $(\mathrm{n}=18)$ on a feed-pad ${ }^{1}$

\begin{tabular}{|c|c|c|c|c|c|c|c|}
\hline $\begin{array}{l}\text { Frequency of social behavior } \\
\text { parameters per feeding session }\end{array}$ & \multicolumn{7}{|c|}{ Main effect } \\
\hline \multicolumn{8}{|l|}{ Aggressive behaviors } \\
\hline Mean & $0.9^{\mathrm{b}}$ & $0.8^{\mathrm{ab}}$ & $0.6^{\mathrm{a}}$ & 0.030 & 0.7 & 0.8 & 0.667 \\
\hline $\mathrm{SD}^{2}$ & 0.9 & 0.9 & 0.7 & 0.059 & 0.9 & 0.9 & 0.947 \\
\hline $\mathrm{SD}^{2}$ & $1.2^{\mathrm{b}}$ & $1.1^{\mathrm{b}}$ & $0.8^{\mathrm{a}}$ & 0.003 & 1.0 & 1.1 & 0.210 \\
\hline
\end{tabular}

${ }^{\mathrm{a}, \mathrm{b}}$ Within rows, means with different superscripts are significantly different $(P<0.05)$.

${ }^{1}$ Data were predicted means and SD.

${ }^{2}$ Indicates cow-to-cow variation of a relevant variable within the group of 12 cows at each treatment.

\section{DISCUSSION}

Construction of permanent feed-out areas to offer mixed rations to grazing cows (PMR feeding systems) is one of the advanced feeding technologies recently introduced to dairy farming in Australia to efficiently present supplemental nutrients (Moran and McDonald, 2010; Auldist et al., 2013; Wales et al., 2013). However, constructing a feed-pad is capital-intensive and that capital cost is accompanied by other expenses, including costs of building feed barriers at the feed face and purchasing equipment such as a tractor and mixer wagon to prepare and deliver mixed rations; thus, a permanent feed-out area needs to be considered as an integral part of the feeding system and needs to be operated under skilled management to optimize the returns on assets (Ho et al., 2013).

However, available feeding space per cow and use of feed barriers on the feed-pad vary from farm to farm due to variations in management decisions. This paper provides the first information about the potential for influencing feeding and social behaviors in PMR-fed dairy cows on a feed-pad via the provision of feed barriers or by changing the feeding space over the recommended range.
The first hypothesis tested in this experiment was that increasing the feeding space from 0.6 to 0.75 to $1.0 \mathrm{~m}$ per cow on a feed-pad would improve feeding behavior as a result of decreased agonistic interactions in group-fed dairy cows. With increasing feeding space, both feeding time percentage and mean feeding bout length increased and feeding bout frequency decreased. At the same time, less aggressive and submissive behaviors were observed as feeding space increased. Thus, the first hypothesis is supported. With the increase in feeding space, decreased aggressive and submissive behaviors in loose-housed dairy cows have been noted by many researchers (DeVries et al., 2004; Huzzey et al., 2006). This reduction in agonistic interactions was likely due to the increased inter-cow distances, with more room to eat and less social hindrance at higher space allowances (DeVries et al., 2004). As a consequence, cow feeding time increased and feeding bout frequency decreased in relation to the total time feed was available. This finding is in agreement with the reports of Olofsson (1999), DeVries et al. (2004), and Huzzey et al. (2006), who demonstrated substantial increases in feeding time of dairy cows as feeding space increased, which resulted in reduced competition for feed. However, the increase in cow feeding time was considerably

Table 6. Changes in heart rate and heart rate variability (as measured by RMSSD) with different feeding space allowances and provision of feed barriers on a feed-pad ${ }^{1}(n=18)$

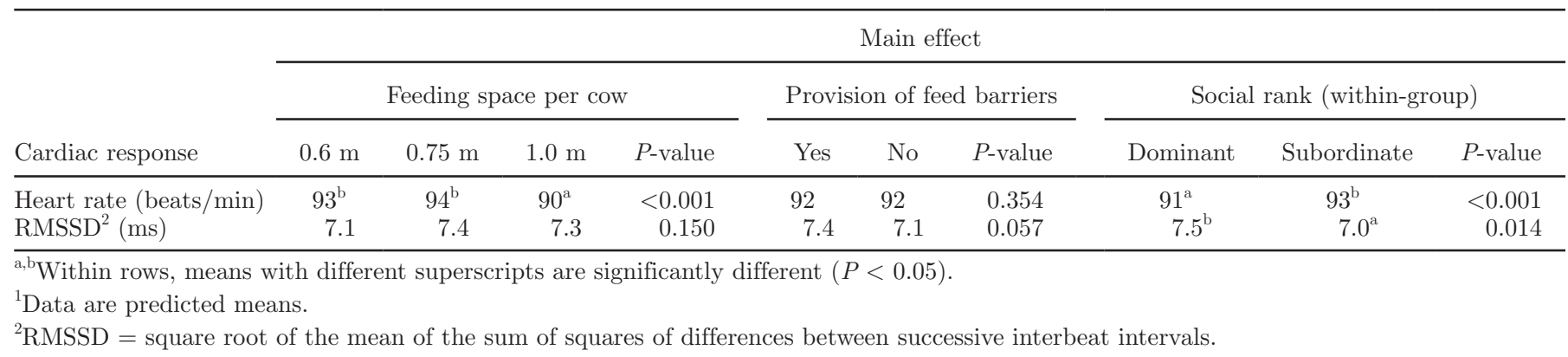


less in the current experiment than in previous reports. These smaller effects compared with previous reports may be results of cows' limited access to a PMR and cows having been already habituated to eating faster, particularly the subordinate cows, which had less access to feed during competitive feeding and no opportunity to shift their feeding times to less competitive hours within the day. It resulted in smaller effects in mean cow feeding times as space allowance increased compared with studies conducted with intensively housed cows that had continuous access to feed, albeit delivered twice daily (DeVries et al., 2004; Huzzey et al., 2006). Interestingly, Keys et al. (1978) and Longenbach et al. (1999) reported on housed dairy heifers with limited feed access; when they lack adequate space, the level of competition between cows at the feed bunk increases, time spent feeding decreases, and variability in growth between heifers increases. Those reports further confirm the findings of the current experiment, where cows had limited access to a mixed ration between the bouts of grazing. Even though 0.60 to $0.76 \mathrm{~m}$ of linear feeding space per cow on a feed-pad is considered adequate for dairy cows in Australia (O'Keefe et al., 2010), the present study provides evidence that when cows are provided more feeding space they are more likely to gain equal access to feed due to the decline in agonistic interactions.

Regardless of the amount of feeding space allowed, dominant cows spent more time eating at each feeding session than did subordinate cows. Interestingly, when feeding space increased from 0.6 to 0.75 to 1.0 $\mathrm{m}$ per cow, subordinate cows showed a significant increase in feeding time. This was probably because socially dominant cows gained more access to the feed at higher levels of competition and when the level of competition was reduced as a result of increased feeding space subordinate cows benefitted most and had fewer withdrawals and more opportunity to consume feed. This concurs with the findings of Olofsson (1999) and DeVries et al. (2004), who reported that providing more feeding space improves access to fresh feed, particularly for subordinate cows. We further found that within-group variation in both feeding time and feeding bout frequency decreased with increasing feeding space, providing more evidence to substantiate the explanation that cows gained more equal access to feed at higher space allowances. Thus, we speculate that this improved access to feed on the feed-pad may lead to increased consistency in DMI throughout the herd and a subsequent increase in productivity in the milking herd. However, we were unable to test the effects on DMI and milk production variations of these treatments, because of the short duration of the treatment periods.
Hence, we recommend further research to be conducted to validate this explanation.

The second hypothesis tested in this experiment was that at a given feeding space allowance on the feedpad, feed barriers that provide physical separation between adjacent cows would improve feeding activity because of the decrease in agonistic interactions. Although the frequency of aggressive behaviors was not affected, the frequency of submissive behaviors (displacements) decreased significantly with the use of feed barriers, irrespective of the feeding space provided. Consequently, use of feeding barriers improved cow feeding activity by increasing feeding time and decreasing feeding bout frequency. Thus, the second hypothesis is supported. When cows are fed in a group, they often displace one another by swinging and butting with their heads (Huzzey et al., 2006). In the current experiment, the hoop-style palisades provided a division between the necks of the adjacent cows, thus preventing lateral swinging motions and resulting in fewer displacements. In contrast, at an open feed trough with no feed barriers, cows had no restrictions to move their heads or bodies, which resulted in more confrontations. Moreover, at lower space allowances such as at 0.6 and $0.75 \mathrm{~m}$ of trough space per cow, cows were feeding closer together at the open feed trough, due to both reduced inter-cow distances and cows' gregarious behavior (Manson and Appleby, 1990). As a result, a single aggressive act could lead to several cows being displaced from the trough. Fewer displacements due to the presence of feed barriers indicate that cow feeding was interrupted less frequently, resulting in longer feeding bouts and reduced feeding bout frequencies. This is also evident for milk-fed calves: Jensen et al. (2008) demonstrated that barriers placed between teat buckets can reduce competition in paired-housed calves during a feeding event. We also found that subordinate cows appeared to benefit most from the physical separation provided by the palisades and had increased feeding times compared with the open feed trough. This is in accordance with the report of Bouissou (1970), which noted that dividers separating the heads of adjacent cows at the feed trough allowed subordinate cows to feed for longer periods of time. A review conducted by von Keyserlingk and Weary (2010) reported that feed stalls that provide a partition between feeding stations reduce aggression and competitive displacements, effects that are greatest for socially low-ranked cows. Hence, it could be surmised that when cows are physically separated at the feed trough, socially lowranked cows are protected from aggressive encounters, resulting in improved feeding time at group-feeding. 
Risks associated with feeding higher amounts of cereal-based concentrates in dairy cows include the development of subacute ruminal acidosis and its sequelae, including laminitis (Nocek, 1997). Although PMR feeding is considered to reduce the acidotic effects of concentrates and the subsequent risk of laminitismediated hoof problems (Moran and McDonald, 2010), the extended time that cows spend standing and moving on abrasive concrete surfaces may result in an increased rate of claw horn wear and higher incidence of lameness. As suggested by Leonard et al. (1998) in a preliminary study, these conditions could be exacerbated when cows engage in aggressive encounters. Even though the findings of the current experiment have shown that the feeding space allowance and the use of feed barriers affect the number of agonistic interactions during group feeding, no data were collected for its effects on cow foot health. Hence, further research is warranted to substantiate this suggestion.

The third hypothesis tested in this experiment was that an increase in feeding space from 0.6 to 0.75 to $1.0 \mathrm{~m}$ or the addition of feed barriers would reduce the physiological stress caused by competition, as measured by HR and HRV. Changes in HR (Hopster et al., 1995; Arnold et al., 2007) and HRV (Mohr, 2002; Hagen et al., 2005; Gygax et al., 2008) in dairy cows have previously been used to measure stress from physical, pathological, and psychological origins. In the current study, HR was significantly reduced and RMSSD tended to increase with the increase of available feed space. Therefore, in line with our hypothesis, the amount of stress load on cows was alleviated when the feeding space was increased, as a consequence of reduced competition for feed. These results corresponded with the feeding and social behaviors discussed previously. Further, subordinate cows showed a pronounced increase in HR and a greater decrease in RMSSD compared with dominant cows, irrespective of the treatment effects. Thus, it appears that these socially low-ranked cows showed a greater fear-related stress response to neighboring dominant cows and to their aggressive acts during feeding.

Contrary to our hypothesis that feed barriers would decrease the level of competition among cows, resulting in lower stress responses, this experiment showed no effect of feed barriers on physiological stress responses as measured by HR and HRV. Interestingly, use of feed barriers at a given feed space allowance reduced the number of displacements, resulting in reduced feeding bout frequency and increased feeding times in relation to the total time that feed was available. This apparent dissociation between physiological responses and behavioral responses could be due to the fear-related stress responses in subordinate cows to the aggressive interactions, although dominant cows were less successful in initiating agonistic interactions when feed barriers were present at a given space allowance.

\section{CONCLUSIONS}

This study provides insight into how feed space allowance and the provision of feed barriers interact to affect feeding and social behaviors of dairy cows fed mixed rations on a feed-pad between bouts of grazing. Increasing the feeding space from 0.6 to 0.75 to $1.0 \mathrm{~m}$ improved both feeding and social behaviors as a consequence of reduced competition for feed. This indicates that when cows are provided with more feeding space than that currently recommended by industry, they are more likely to gain equal access to feed due to the decline in agonistic interactions. Use of feed barriers that provide physical separation between adjacent cows on the feed-pad further reduced competition at the feed trough. Further, subordinate cows that were most affected at higher levels of competition during group feeding benefited most from feed barriers and increased feeding space allowances. Future research is recommended to examine the effects of increased feeding space and use of feed barriers on DMI, milk production, and their variability, and on hoof health of grazing dairy cows partially fed on a feed-pad. This would provide a better understanding of long-term implications of these feeding strategies and may aid in improving dairy cow productivity and welfare in PMR feeding systems.

\section{ACKNOWLEDGMENTS}

The authors are grateful to J. S. Greenwood, M. M. Wright, G. Morris, L. Dorling, T. Hookey, A. McDonald, S. Ziero, G. Phillips, and M. Norman (all from DEPI-Ellinbank, VIC, Australia), and DEPIEllinbank farm staff for cow feeding and husbandry. The assistance from S. Borg and B. Schirmer (both from DEPI-Werribee), and M. Conley (University of Melbourne) in setting up video recording equipment is gratefully acknowledged. This study was co-funded by DEPI, University of Melbourne, and Dairy Australia (Melbourne, VIC, Australia).

\section{REFERENCES}

Arnold, N. A., K. T. Ng, E. C. Jongman, and P. H. Hemsworth. 2007. The behavioural and physiological responses of dairy heifers to tape-recorded milking facility noise with and without a pretreatment adaptation phase. Appl. Anim. Behav. Sci. 106:13-25.

Auldist, M. J., L. C. Marett, J. S. Greenwood, M. Hannah, J. L. Jacobs, and W. J. Wales. 2013. Effects of different strategies for feeding supplements on milk production responses in cows grazing a restricted pasture allowance. J. Dairy Sci. 96:1218-1231. 
Bargo, F., L. D. Muller, G. A. Varga, J. E. Delahoy, and T. W. Cassidy. 2002a. Performance of high producing dairy cows with three different feeding systems combining pasture and total mixed rations. J. Dairy Sci. 85:2948-2963.

Bargo, F., L. D. Muller, G. A. Varga, J. E. Delahoy, and T. W. Cassidy. 2002b. Ruminal digestion and fermentation of high-producing dairy cows with three different feeding systems combining pasture and total mixed rations. J. Dairy Sci. 85:2964-2973.

Bouissou, M. F. 1970. Role du contact physique dans la manifestation des relations hierarchiques chez les bovins, consequences pratiques. Ann. Zootech. 19:279-285.

Davison, T., and J. Andrews. 1997. Feedpads Down Under. Queensland Department of Primary Industries, Brisbane, Australia.

DeVries, T. J., and M. A. G. von Keyserlingk. 2006. Feed stalls affect the social and feeding behavior of lactating dairy cows. J. Dairy Sci. 89:3522-3531.

DeVries, T. J., M. A. G. von Keyserlingk, and D. M. Weary. 2004. Effect of feeding space on the inter-cow distance, aggression, and feeding behavior of free-stall housed lactating dairy cows. J. Dairy Sci. 87:1432-1438.

Dickson, D. P., G. R. Barr, and D. A. Wieckert. 1967. Social relationship of dairy cows in a feed lot. Behavior 29:195-203.

Doyle, P. T., and C. R. Stockdale. 2011. Dairy farm management systems: Seasonal, pasture-based, dairy cow breeds. Pages 29-37 in Encyclopaedia of Dairy Sciences. Vol. 2. J. W. Fuquay, P. F. Fox, and P. L. H. McSweeney, ed. Academic Press, Amsterdam, the Netherlands.

Earle, D. F. 1976. A guide to scoring dairy cow condition. J. Agric. Vic. 74:228-231.

Endres, M. I., T. J. DeVries, M. A. G. von Keyserlingk, and D. M. Weary. 2005. Effect of feed barrier design on the behavior of loosehoused lactating dairy cows. J. Dairy Sci. 88:2377-2380.

Friend, T. H., C. E. Polan, and M. L. McGilliard. 1977. Free stall and feed bunk requirements relative to behavior, production and individual feed intake in dairy cows. J. Dairy Sci. 60:108-116.

Greter, A. M., R. S. Westerveld, T. F. Duffield, B. W. McBride, T. M. Widowski, and T. J. DeVries. 2013. Short communication: Effects of frequency of feed delivery and bunk space on the feeding behavior of limit-fed dairy heifers. J. Dairy Sci. 96:1803-1810.

Gygax, L., I. Neuffer, C. Kaufmann, R. Hauser, and B. Wechsler. 2008. Restlessness behavior, heart rate and heart-rate variability of dairy cows milked in two types of automatic milking systems and autotandem milking parlours. Appl. Anim. Behav. Sci. 109:167-179.

Hagen, K., J. Langbein, C. Schmied, D. Lexer, and S. Waiblinger. 2005. Heart rate variability in dairy cows - Influences of breed and milking system. Physiol. Behav. 85:195-204.

Harville, D. A. 1974. Nearly optimal allocation of experimental units using observed covariate values. Technometrics 16:589-599.

Hetti Arachchige, A. D., A. D. Fisher, M. J. Auldist, W. J. Wales, and E. C. Jongman. 2013. Effects of different systems of feeding supplements on time budgets of cows grazing restricted pasture allowances. Appl. Anim. Behav. Sci. 148:13-20.

Ho, C. K. M., M. Newman, D. E. Dalley, S. Little, and W. J. Wales. 2013. Performance, return and risk of different dairy systems in Australia and New Zealand. Anim. Prod. Sci. 53:894-906.

Hopster, H., J. M. O'Connell, and H. J. Blokhuis. 1995. Acute effects of cow-calf separation on heart rate, plasma cortisol and behavior in multiparous dairy cows. Appl. Anim. Behav. Sci. 44:1-8.

Huzzey, J. M., T. J. DeVries, P. Valois, and M. A. G. von Keyserlingk. 2006. Stocking density and feed barrier design affect the feeding and social behavior of dairy cattle. J. Dairy Sci. 89:126-133.

Jensen, M. B., A. M. de Passillé, M. A. G. von Keyserlingk, and J. Rushen. 2008. A barrier can reduce competition over teats in pairhoused milk-fed calves. J. Dairy Sci. 91:1607-1613.

Keys, J. E., R. E. Pearson, and P. D. Thompson. 1978. Effect of feed bunk stocking density on weight gains and feeding behavior of yearling Holstein heifers. J. Dairy Sci. 61:448-454.

Leonard, F. C., I. Stienezen, and K. J. O'Farrell. 1998. Overcrowding at the feeding area and effects on behavior and claw health in
Friesian heifers. Pages 40-41 in Proc. 10th Int. Symp. Lameness Rumin., Lucerne, Switzerland. Univ. Zurich, Zurich, Switzerland.

Longenbach, J. I., A. J. Heinrichs, and R. E. Graves. 1999. Feed bunk length requirements for Holstein dairy heifers. J. Dairy Sci. 82:99-109.

Malik, M., J. T. Bigger, A. J. Camm, R. E. Kleiger, A. Malliani, A. J. Moss, and P. J. Schwartz.; Task Force of the European Society of Cardiology and the North American Society of Pacing and Electrophysiology. 1996. Heart rate variability: Standards of measurement, physiological interpretation and clinical use. Eur. Heart J. $17: 354-381$.

Manson, F. J., and M. C. Appleby. 1990. Spacing of dairy cows at a food trough. Appl. Anim. Behav. Sci. 26:69-81.

Mendl, M., A. J. Zanella, and D. M. Broom. 1992. Physiological and reproductive correlates of behavioral strategies in female domestic pigs. Anim. Behav. 44:1107-1121.

Moberg, G. P., and J. A. Mench. 2000. The Biology of Animal Stress: Basic Principles and Implications for Animal Welfare. CAB International, New York, NY.

Mohr, E., J. Langbein, and G. Nürnberg. 2002. Heart rate variability-A noninvasive approach to measure stress in calves and cows. Physiol. Behav. 75:251-259.

Moran, J., and S. McDonald. 2010. The role of feedpads in pasturebased dairy farming. Page 31 in Feedpads for Grazing Dairy Cows. CSIRO Publishing, Victoria, Australia.

Morgan, K. N., and C. T. Tromborg. 2007. Sources of stress in captivity. Appl. Anim. Behav. Sci. 102:262-302.

National Health and Medical Research Council. 2004. Australian Code of Practice for the Care and Use of Animals for Scientific Purposes. 7th ed. Australian Government, Canberra, Australia.

Nocek, J. E. 1997. Bovine acidosis: Implication on laminitis. J. Dairy Sci. 80:1005-1028.

O'Connell, N. E., C. P. Ferris, D. C. Patterson, and C. S. Mayne. 2010. Effect of feed barrier design and feed space allowance on performance and behavioural parameters in dairy cows. Appl. Anim. Behav. Sci. 127:20-27.

O'Keefe, M., P. Chamberlain, S. Chaplin, T. Davison, J. Green, and R. Tucker. 2010. Guidelines for Victorian Dairy Feedpads and Freestalls. 1st ed. Department of Primary Industries Victoria, Echuca, Australia.

Olofsson, J. 1999. Competition for total mixed diets fed for ad libitum intake using one or four cows per feeding station. J. Dairy Sci. 82:69-79.

Proudfoot, K. L., D. M. Veira, D. M. Weary, and M. A. G. von Keyserlingk. 2009. Competition at the feed bunk changes the feeding, standing, and social behavior of transition dairy cows. J. Dairy Sci. 92:3116-3123.

Sloten, J., P. Verdonck, M. Nyssen, J. Haueisen, M. P. Tarvainen, J. P. Niskanen, J. A. Lipponen, P. O. Ranta-aho, and P. A. Karjalainen. 2009. Kubios HRV - A software for advanced heart rate variability analysis. Pages 1022-1025 in Proc. 4th Eur. Conf. Int. Fed. Med. Biol. Eng. Springer, Berlin, Germany.

Stewart, M., K. J. Stafford, S. K. Dowling, A. L. Schaefer, and J. R. Webster. 2008. Eye temperature and heart rate variability of calves disbudded with or without local anaesthetic. Physiol. Behav. 93:789-797.

von Borell, E., J. Langbein, G. Després, S. Hansen, C. Leterrier, J. Marchant-Forde, R. Marchant-Forde, M. Minero, E. Mohr, A. Prunier, D. Valance, and I. Veissier. 2007. Heart rate variability as a measure of autonomic regulation of cardiac activity for assessing stress and welfare in farm animals - A review. Physiol. Behav. 92:293-316.

von Keyserlingk, M. A., and D. M. Weary. 2010. Review: Feeding behaviour of dairy cattle: Measures and applications. Can. J. Anim. Sci. 90:303-309.

Wales, W. J., L. C. Marett, J. S. Greenwood, M. M. Wright, J. B. Thornhill, J. L. Jacobs, C. K. M. Ho, and M. J. Auldist. 2013. Use of partial mixed rations in pasture-based dairying in temperate regions of Australia. Anim. Prod. Sci. 53:1167-1178. 